ISSN 1980-5098

\title{
AVALIAÇÃO DO DESEMPENHO E CUSTOS DE DOIS SISTEMAS DE CABOS AÉREOS NA EXTRAÇÃO DE MADEIRA DE EUCALIPTO
}

\author{
PERFORMANCE AND COST EVALUATION OF TWO CABLE YARDER SYSTEMS IN THE \\ EXTRATION OF EUCALYPTUS WOOD
}

\author{
Ilvânio Luiz Guedes ${ }^{1}$ Edvaldes José do Amaral ${ }^{2}$ Elton Da Silva Leite ${ }^{3}$ Haroldo Carlos Fernandes ${ }^{4}$ \\ Cleverson de Mello Sant'Anna ${ }^{5}$
}

\begin{abstract}
RESUMO
Objetivou-se com este trabalho avaliar o desempenho e determinar os custos de dois sistemas de cabos aéreos na extração de madeira de eucalipto em região montanhosa. A análise técnica baseou-se em estudo de tempos e movimentos do ciclo operacional e produtividade de dois sistemas de extração: Sistema 1 (trator Massey Ferguson 297 e guincho Penzsaur K301-T) e Sistema 2 (escavadora Caterpillar 320L e guincho Koller), operando em plantios com idade de sete anos e de segunda rotação. A produtividade média na extração de madeira foi de $13,63 \mathrm{~m}^{3} \mathrm{~h}^{-1}$ para o Sistema 1 e $14,70 \mathrm{~m}^{3} \mathrm{~h}^{-1}$ para o Sistema 2, para distância média de $150 \mathrm{~m}$, eficiência operacional de $46 \%$ e $51 \%$ e disponibilidade mecânica de $91 \%$ e $59 \%$, respectivamente. O aumento da distância de extração implicou em aumento no tempo para realizar as atividades do ciclo operacional e em redução da produtividade. O Sistema 2 mostrou-se mais produtivo, porém, apresentou maior custo de produção.
\end{abstract}

Palavras-chave: extração florestal; teleféricos; produtividade.

\begin{abstract}
The objective of this study was to evaluate the performance and determine the costs of two cable yarder systems in the extraction of eucalyptus wood in mountainous regions. The technical analysis was based on the study of times and motions of the operating cycle and productivity of two extraction systems: System 1 (tractor Massey Ferguson 297 and winch Penzsaur K301-T) and System 2 (excavator Caterpillar 320L and winch Koller), operating in plantations aged seven years old and of second rotation. Average productivity in logging was $13.63 \mathrm{~m}^{3} \mathrm{~h}^{-1}$ for System 1 and $14.70 \mathrm{~m}^{3} \mathrm{~h}^{-1}$ for System 2 for a distance of $150 \mathrm{~m}$ on average, operating efficiency of $46 \%$ and $51 \%$ and mechanical availability of $91 \%$ and $59 \%$, respectively. The increased extraction distance resulted in increased time to perform the activities of the operating cycle and reduced productivity. System 2 was more productive, but showed higher production costs.
\end{abstract}

Keywords: forest extraction; yarder; productivity.

\section{INTRODUÇÃO}

A colheita de madeira é a fase de maior importância no setor florestal, dada a elevada participação

1 Engenheiro de Produção, Celulose Nipo Brasileira S.A. - CENIBRA, Rodovia BR 381, km 172, Distrito de Perpétuo Socorro, CEP 35196-000, Belo Oriente (MG), Brasil. ilvanio.guedes@cenibra.com.br

2 Engenheiro Mecânico, Celulose Nipo Brasileira S.A. - CENIBRA, Rodovia BR 381, km 172, Distrito de Perpétuo Socorro, CEP 35196-000, Belo Oriente (MG), Brasil. edvaldes.amaral@cenibra.com.br

3 Engenheiro Florestal, Dr., Professor Adjunto do Centro de Ciências Agrárias Ambientais e Biológicas da Universidade Federal do Recôncavo da Bahia, Rui Barbosa, 710, CEP 44380-000 (BA), Brasil. eltonsleite@gmail.com

4 Engenheiro Agrícola, Dr. Professor Titular do Dep. Engenharia Agrícola da Universidade Federal de Viçosa, Av. P. H. Rolfs, s/n, Campus Universitário, CEP 36570-000, Viçosa (MG), Brasil. haroldo@ufv.br

5 Engenheiro Florestal, Dr. Professor do Departamento de Engenharia Florestal Universidade Federal de Viçosa, Av. P. H. Rolfs, s/n, Campus Universitário, CEP 36570-000, Viçosa (MG), Brasil. cleverson@ufv.br

Recebido para publicação em 31/10/2014 e aceito em 20/10/2015

Ci. Fl., v. 27, n. 2, abr.-jun., 2017 
no custo final do produto e aos riscos envolvidos nessa atividade (BIRRO et al., 2002). A colheita e o transporte florestal podem alcançar $50 \%$ do custo final da madeira colocada na indústria (MACHADO, 1989; LOPES, 2001).

Das principais etapas da colheita destaca-se a extração florestal. Os custos de extração em áreas acidentadas são elevados, por isso o planejamento deve ser bem detalhado, sendo importante o emprego de máquinas específicas, destacando-se a utilização dos cabos aéreos (PENNA, 2009).

O sistema de cabos aéreos ainda não é muito difundido, sendo uma tecnologia pouco utilizada pelas empresas brasileiras, porém, a crescente demanda e elevação do valor da madeira, tornou este sistema viável economicamente na exploração de terrenos com elevada inclinação, justificando a mecanização por cabos aéreos (PAULA et al., 2014; LOPES et al., 2011). Além disto, a crescente valorização de áreas planas favoreceu a exploração em áreas acidentadas, que por vezes eram áreas ociosas nas empresas florestais.

Segundo Leite et al. (2012), o sistema de extração por cabos pode ser um aliado na redução da erosão em áreas declivosas e otimização do local de depósito da madeira às margens das estradas, além de fornecer boas condições ergonômicas, contribuindo para ganhos de produção. Conway (1976) destaca que este sistema garante menor densidade de estradas e maior aproveitamento da área plantada, sendo capaz de retirar toras em áreas de declividade acentuada ou alagadas, nas quais os tratores florestais são inoperantes. Nas condições desfavoráveis, que não permitem o uso de sistemas habituais, o uso de cabos aéreos destacase pelos aspectos ambientais e do baixo investimento financeiro despendido, sendo essencial o conhecimento da produtividade (SIMÕES; FENNER; BANTEL, 2010).

Neste sentido, a extração com cabos aéreos é notadamente um dos meios para viabilizar a colheita em áreas florestais em que o trânsito de máquinas não é possível, tornando indispensáveis os conhecimentos técnicos para maximizar a produtividade e minimizar os impactos ambientais e econômicos. Sendo assim, objetivou-se, neste estudo, avaliar o desempenho e determinar os custos de dois sistemas de cabos aéreos na extração de madeira de eucalipto de segunda rotação em região montanhosa.

\section{MATERIAL E MÉTODO}

\section{Caracterização da área de estudo}

A pesquisa foi realizada no município de Antônio Dias - MG, nas coordenadas UTM 721.000m W e $7.849 .000 \mathrm{~m} \mathrm{~S}$, zona 23 sul, datum Sirgas 2000. A coleta de dados foi realizada em uma área de 16,07 ha em povoamentos de clones híbridos de Eucalyptus grandis com Eucalyptus urophylla, de sete anos de idade, em regime de segunda rotação, com volume da floresta de $267,72 \mathrm{~m}^{3} \mathrm{ha}^{-1}$ e volume por árvore de $0,313 \mathrm{~m}^{3}$. A declividade do terreno variou de $31,1 \%$ a $77,8 \%$ e $58,9 \%$ de média. Os solos predominantes na área de estudo foram classificados como Latossolo Vermelho-Amarelo (SOIL SURVEY STAFF, 2010). Foi realizada roçada pré-corte na área, visando à padronização das áreas de extração.

O sistema de derrubada e processamento foram realizadas com o uso de motosserra e machadinhas, com direcionamento de queda das árvores em ângulos de $35^{\circ}$ a $45^{\circ}$ no sentido do declive do terreno, no formato tipo "espinha de peixe".

\section{Descrição dos sistemas de cabos aéreos}

O Sistema 1 era composto por trator agrícola de pneus da marca Massey Fergusson, modelo 297, motor Perkins 1006-6, 6 cilindros, potência nominal de $120 \mathrm{cv}(79,47 \mathrm{~kW})$ e guincho duplo com carretéis para cabo de tração da marca Penzsaur, modelo K301-T, com torre de 8,8 m de altura, retorno de $400 \mathrm{~m}$ de comprimento e diâmetro de $10 \mathrm{~mm}$, força de tração de $26 \mathrm{kN}$, sistema de freio hidráulico, engrenagem planetária com freio para suporte com cabo-mestre e carro automático Koller para tração e retorno, modelo Trolley SKA 1,5 e comandos do cabo aéreo situam-se na parte traseira do trator, logo após o cabo (Figura 1a).

O Sistema 2 era composto por escavadora hidráulica Caterpillar 320L, motor Caterpillar modelo 3066T, 6 cilindros com potência nominal de $128 \mathrm{cv}(84,77 \mathrm{~kW})$, com torre na ponta do braço hidráulico da máquina de $10 \mathrm{~m}$ de altura. Utilizou-se um guincho duplo da marca Koller com carretéis para cabo de tração 


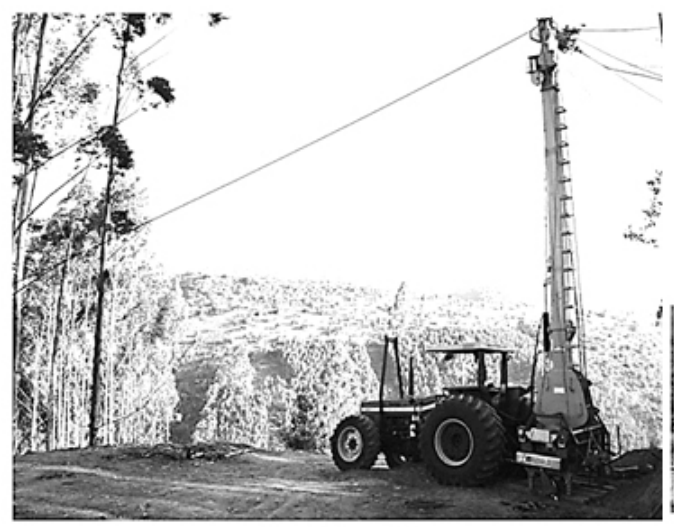

(a) Sistema 1

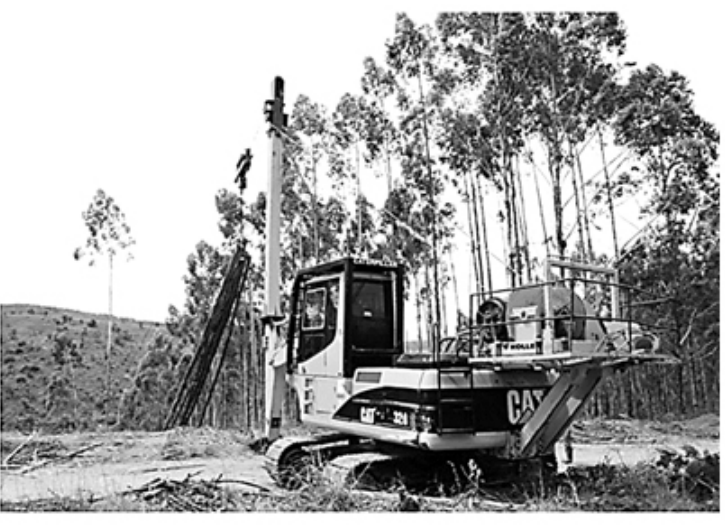

(b) Sistema 2

FIGURA 1: Sistema 1 - trator Massey Ferguson 297 e guincho Penzsaur K301-T (a); Sistema 2 - escavadora Caterpillar 320L e guincho Koller (b).

FIGURE 1: System 1 - tractor Massey Ferguson 297 and yarder Penzsaur K301-T (a); System 2 - excavator Caterpillar 320L and yarder Koller (b).

e retorno de 500 metros de comprimento e diâmetro de $10 \mathrm{~mm}$ e força de tração $26 \mathrm{kN}$, com sistema de freio hidráulico e comandos eletrônicos, engrenagem planetária com freio para suporte com cabo mestre e carro automático Koller para tração e retorno, modelo Trolley SKA 2,5, os comandos do cabo aéreo situam-se na cabina da escavadora (Figura 1b).

Nos sistemas, utilizou-se um operador e dois ajudantes que amarravam os estropos (cabos de amarração) nas toras e um ajudante com a função de conectar o cabo de tração aos estropos e comunicar-se com o operador por meio de rádio. O operador do Sistema 1 realizava a soltura dos cabos após a extração dos fustes. No Sistema 2 utilizou-se um auxiliar específico para realizar esta atividade, visto que a elevação do posto de trabalho de 2,60 m aumentaria muito o tempo de soltura dos cabos. Depois de extraídas, as toras eram arrastadas por um clambunk skidder e distribuídas nas margens das estradas.

\section{Coleta de dados}

A coleta de dados foi realizada no período de 65 dias úteis no turno das 7 às 16 horas, exceto na presença de chuvas, registrando as ocorrências de jornada de trabalho, horas trabalhadas por turno, consumo de combustível, pausas técnicas e atividades do ciclo operacional. As máquinas iniciavam abastecidas e ao final do turno eram reabastecidas, esta diferença representou o consumo diário de combustível, o quociente deste valor pelo número de hora determinou o consumo médio de combustível, em $\mathrm{L} \mathrm{h}^{-1}$.

\section{Ciclo operacional}

O ciclo operacional foi subdividido nos seguintes elementos parciais:

1) Deslocamento vazio - intervalo de descer o carrinho após a descarga até a sua chegada próximo à carga a ser arrastada.

2) Carregamento - intervalo de ação para passar o cabo e engatar das toras, amarrar chockers.

3) Afastamento - intervalo de tempo em que os auxiliares se deslocavam para pontos seguros.

4) Acoplamento - intervalo de tempo de arraste inicial das árvores até que o suporte (pêndulo) fosse encaixado ao carrinho.

5) Deslocamento carregado - início do movimento do carrinho até atingir $2 \mathrm{~m}$ da torre, sendo o mesmo freado pelo operador.

6) Descarregamento - intervalo de tempo entre a descida dos cabos de amarração com as toras até o solo, soltura dos cabos de amarração e acoplamento do suporte ao carrinho.

7) Pausas - intervalo de tempo gasto para desprender árvores presa em tocos durante o arraste, tempo 
aguardando o clambunk skidder retirar árvores e paradas para retirada de árvores para aliviar a carga.

\section{Procedimento amostral}

A amostragem foi aplicada para determinar número de observações necessárias (ciclos operacionais) dos sistemas de cabos aéreos de modo a definir o número mínimo para um erro de amostragem máximo de 5\%, por meio da expressão proposta por Conaw (1976) (equação 1). Foram registrados 318 ciclos operacionais para o Sistema 1 e 370 ciclos operacionais para o Sistema 2, o número mínimo de observações era de 131 e 168 para os Sistemas 1 e 2, respectivamente. As atividades foram mensuradas pelo método de tempos contínuos.

$$
\mathrm{n} \geq \frac{\mathrm{t}^{2} * \mathrm{CV}^{2}}{\mathrm{E}^{2}}
$$

Em que: $\mathrm{n}=$ número mínimo de ciclos necessários; $\mathrm{t}=$ valor de $\mathrm{t}$, para o nível de probabilidade desejado e $(n-1)$ graus de liberdade; $C V$ = coeficiente de variação, em porcentagem; $E$ = erro admissível, em porcentagem.

\section{Produtividade}

A medição do volume $\left(\mathrm{m}^{3}\right)$ de madeira extraída foi determinada pela multiplicação do número de fuste por ciclo operacional pelo volume médio das árvores. Assim, a produtividade $\mathrm{em} \mathrm{m}^{3} \mathrm{~h}^{-1}$ foi igual ao volume de madeira extraída dividido pelas horas efetivamente trabalhadas (BIRRO, 2002; OLIVEIRA, 2009; LOPES et al., 2011), determinada pela equação 2.

$$
\text { Prod }=\frac{\mathrm{N} \mathrm{V}}{\mathrm{h}}
$$

Em que: Prod = produtividade $\left(\mathrm{m}^{3} \mathrm{~h}^{-1}\right) ; \mathrm{N}=$ número de árvores extraídas; $\mathrm{V}=$ volume médio por árvore com casca $\left(\mathrm{m}^{3}\right)$; e $\mathrm{h}=$ horas efetivas de trabalho $(\mathrm{h})$.

A identificação das faixas de extração foi determinada pelas árvores do balizamento, dispostas a cada $50 \mathrm{~m}$ de distância umas das outras até atingir $350 \mathrm{~m}$. Assim, as faixas foram representadas pelos pontos centrais: 0 a $50 \mathrm{~m}(25), 50$ a $100 \mathrm{~m}$ (75), 100 a $150 \mathrm{~m}$ (125), 150 a $200 \mathrm{~m}$ (175), 200 a $250 \mathrm{~m}$ (225), 250 a $300 \mathrm{~m}$ (275), 300 a $350 \mathrm{~m}(325)$.

As velocidades das atividades de subir e descer o carrinho foram determinadas pela distância da máquina ao centro da faixa em análise dividido pelo tempo de subida ou de descida do carrinho.

A disponibilidade mecânica é a percentagem do tempo de trabalho programado em que a máquina está mecanicamente apta a realizar trabalho produtivo, desconsiderando-se, portanto, o tempo em que a máquina está em manutenção. Pode ser determinada pela equação 3 (BIRRO, 2002; OLIVEIRA, 2009; LOPES et al., 2011; LEITE et al., 2012).

$$
D M=\frac{\mathrm{ht}-\mathrm{tm}}{\mathrm{ht}} * 100
$$

Em que: $\mathrm{DM}=$ grau de disponibilidade mecânica (\%); tm = tempo de manutenção (h); e ht = horas totais (h).

Considerou-se como eficiência operacional a percentagem do tempo efetivamente trabalhado em relação ao tempo total programado para o trabalho (BIRRO, 2002; OLIVEIRA, 2009; LEITE et al., 2012), expressa pela equação 4 . Os tempos parados e operacionais foram determinados pelo acompanhamento diário das atividades.

$$
E O=\frac{\mathrm{h}}{(\mathrm{h}+\mathrm{hp})} * 100
$$

Em que: $\mathrm{EO}=$ eficiência operacional (\%); $\mathrm{h}$ = horas efetivas de trabalho (h); e hp = horas paradas (h). 


\section{Custo de produção}

Os custos operacionais da extração de madeira com cabo aéreo foram calculados em reais por hora de trabalho $\left(\mathrm{R} \$ \mathrm{~h}^{-1}\right)$, a taxa de câmbio era de 1,00 dólar $=\mathrm{R} \$ 3,10 \mathrm{em} \mathrm{10/06/2015}$. O custo total compreendeu pelo somatório dos custos fixos e dos custos variáveis obtidos pela metodologia proposta pela American Society of Agricultural Engineers (2001) de acordo com Leite et al. (2012) e Simões, Fenner e Bantel (2010). Os componentes do custo estão apresentados na Tabela 1.

TABELA 1: Equações para determinação do custo horário dos sistemas de cabos aéreos.

TABLE 1: Equations for determining the hourly cost of cable yarder systems.

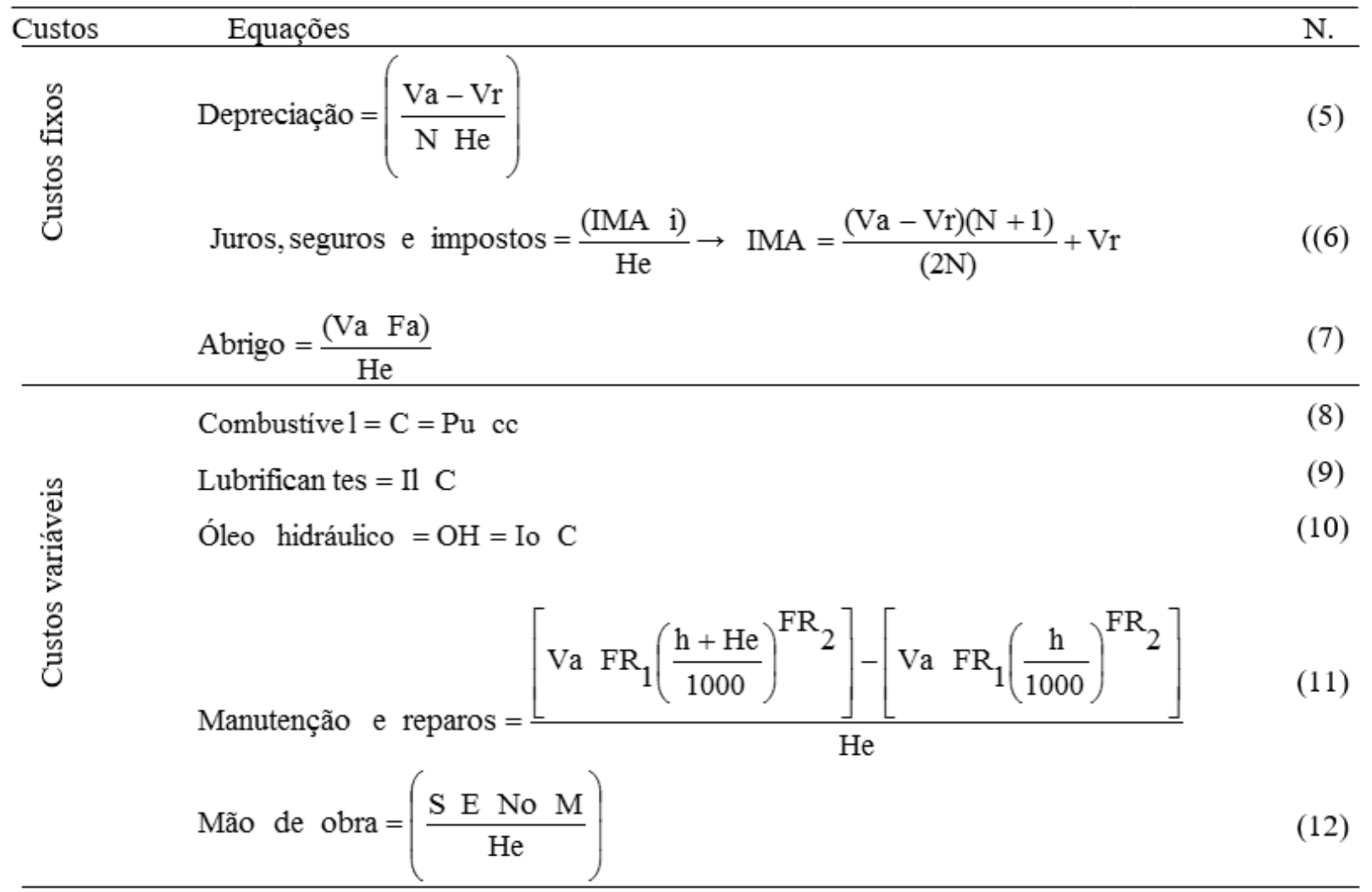

Em que: $\mathrm{Va}=$ valor de aquisição da máquina; $\mathrm{Vr}=$ valor residual, $10 \% \mathrm{Va}(\mathrm{US} \$) ; \mathrm{He}=$ horas efetivas de uso anual; $\mathrm{N}=$ vida útil; i = taxa de juros; IMA = incremento médio anual; $\mathrm{Fa}=$ fator de abrigo; $\mathrm{Pu}=$ preço do combustível por litro; $c c=$ consumo de combustível $\left(\mathrm{L} \mathrm{h}^{-1}\right) ; \mathrm{Il}=$ índice de lubrificantes $(20 \%)$; Io = índice de óleo (20\%); $\mathrm{FR}_{1}=$ fator 1 $(0,003) ; \mathrm{FR}_{2}=$ fator 2 (2); $\mathrm{h}$ = hora que deseja calcular (h); $\mathrm{S}=$ salário mensal do operador (US\$ 721,42); No = número de operadores e ajudantes; $\mathrm{E}=$ encargos; $\mathrm{M}=$ meses no ano (12); Fonte: American Society of Agricultural Engineers (2001).

\section{Análise de dados}

Para a análise de tempos e movimentos utilizou-se o delineamento inteiramente casualizado, para identificar as diferenças entre as atividades do ciclo operacional das máquinas, ao nível de $5 \%$ de probabilidade no teste F. Nos casos em que houve diferença estatística significativa aplicou-se o teste de média Tukey ao nível 5\% de probabilidade, por meio do software SAS 9.2 (SAS INSTITUTE, 2011).

Os resultados do tempo do ciclo operacional, produtividade e custo de produção foram submetidos à análise de regressão para determinar a relação do tempo, produtividade e custos (variáveis dependentes) com a distância de extração (variável independente) para os sistemas de extração, obtendo-se as equações ajustadas no software SAS 9.2 (SAS INSTITUTE, 2011). 
TABELA 2: Tempos médios, em segundos, do ciclo operacional para o Sistema 1 (trator Massey Ferguson 297 e guincho Penzsaur K301-T) e o Sistema 2 (escavadora Caterpillar 320L + guincho Koller).

TABLE 2: Average times, in seconds, of the operational cycle for the System 1 (tractor Massey Ferguson 297 and yarder Penzsaur K301-T) and System 2 (excavator Caterpillar 320L and yarder Koller).

\begin{tabular}{|c|c|c|}
\hline Atividade do ciclo operacional & Sistema 1 & Sistema 2 \\
\hline Deslocamento vazio & $47,0 \mathrm{a}$ & $45,8 \mathrm{a}$ \\
\hline Carregamento & 149,7 a & $157,8 \mathrm{a}$ \\
\hline Afastamento & $25,7 \mathrm{a}$ & $20,5 \mathrm{a}$ \\
\hline Acoplamento & $42,8 \mathrm{a}$ & $27,4 \mathrm{~b}$ \\
\hline Deslocamento carregado & $85,5 \mathrm{a}$ & $62,4 \mathrm{~b}$ \\
\hline Descarregamento & $68,0 \mathrm{a}$ & $59,9 \mathrm{~b}$ \\
\hline Pausas & $27,1 \mathrm{a}$ & $35,8 \mathrm{a}$ \\
\hline Total & 445,8 & 409,6 \\
\hline
\end{tabular}

Em que: Médias seguidas de letras diferentes na linha são diferentes estatisticamente.

\section{RESULTADOS E DISCUSSÃO}

\section{Ciclo operacional}

O tempo médio por ciclo foi de 445,8 s ( 7 min e 26 s) para o Sistema 1 (trator Massey Ferguson 297 e guincho Penzsaur) e 409,6 s (6 min e 49 s) para o Sistema 2 (escavadora Caterpillar 320L e guincho Koller). A Tabela 2 mostra as diferenças significativas do tempo médio em segundos em relação às atividades do ciclo operacional para os Sistemas 1 e 2 . A Figura 2 apresenta os percentuais do ciclo operacional. Cada ciclo apresentava 6,28 e 6,36 árvores por ciclo, em média, para os Sistemas 1 e 2, respectivamente.

\section{Sistema 1}

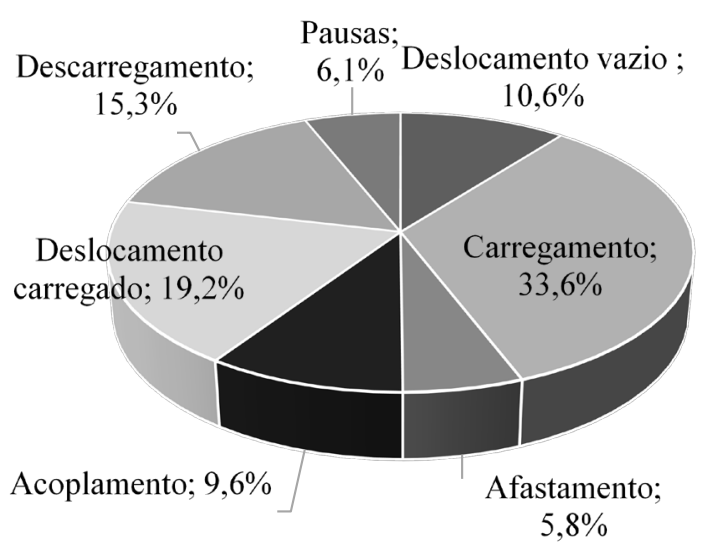

Sistema 2

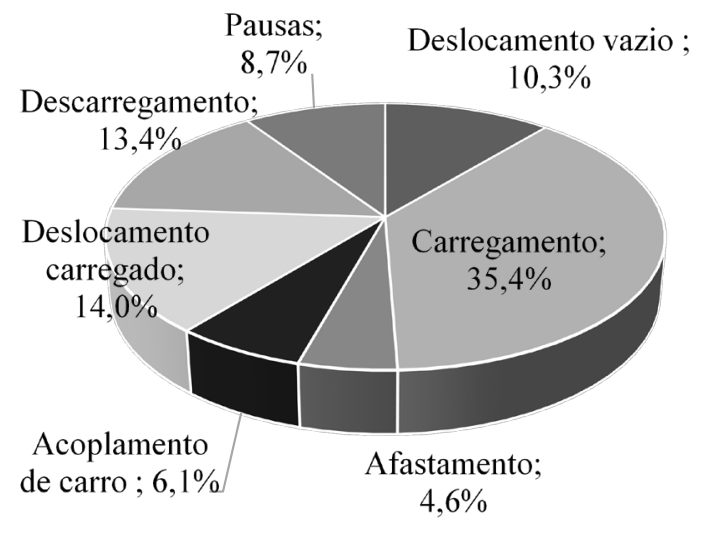

FIGURA 2: Percentual dos tempos operacionais dos sistemas de cabos aéreos na extração de madeira de eucalipto.

FIGURE 2: Percentage of operating time of cable yarder systems for the extraction of eucalyptus wood. 


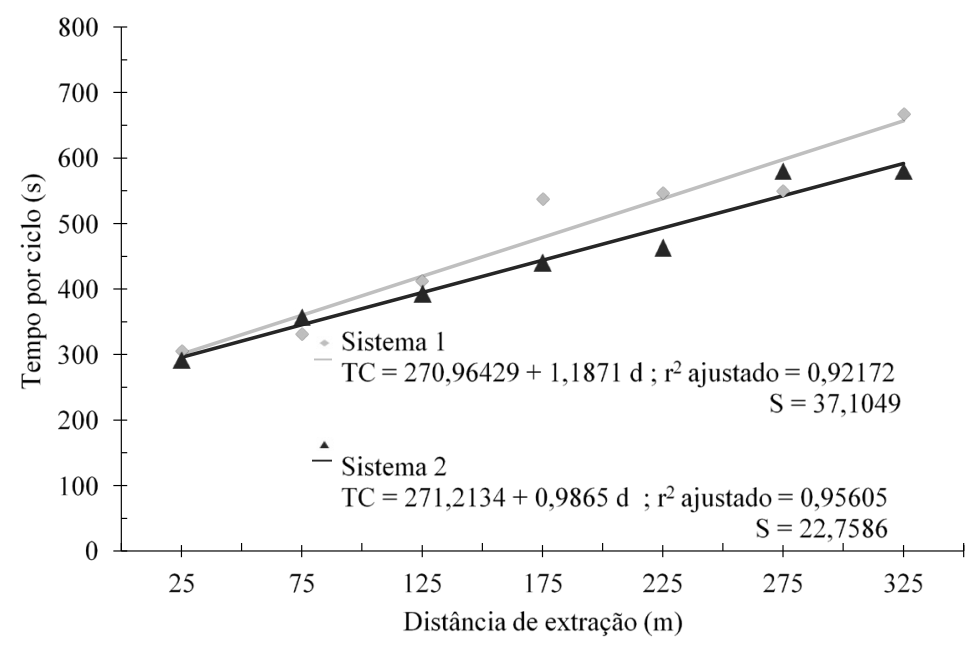

Sistema 1 - Trator Massey Ferguson 297 e guincho Penzsaur K301-T

Sistema 2 - Escavadora Caterpillar 320L e guincho Koller); $\mathrm{y}=$ tempo do ciclo operacional e $\mathrm{x}$ = distância de extração. FIGURA 3: Modelagem do tempo do ciclo operacional em função da distância de extração dos sistemas de cabos aéreos.

FIGURE 3: Time modeling of the operation cycle in function of the extraction distance of cable yarder systems.

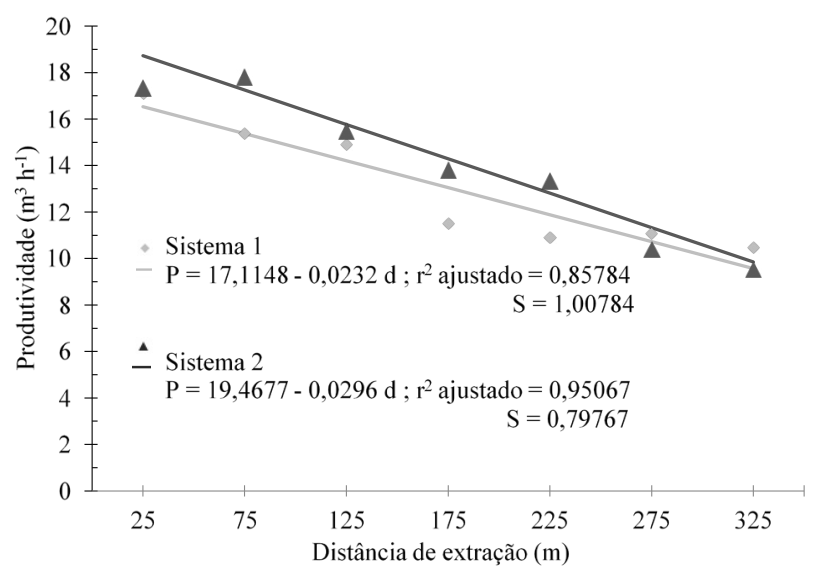

$\mathrm{P}=$ produtividade $; \mathrm{d}=$ distância de extração

FIGURA 4: Modelagem da produtividade em função da distância de extração dos sistemas de cabos aéreos

(Sistema 1- trator Massey Ferguson 297 e guincho Penzsaur K301-T, Sistema 2 - escavadora Caterpillar 320L e guincho Koller).

FIGURE 4: Productivity modeling in function of distance from the extraction of cable yarder systems (System 1- tractor Massey Ferguson 297 and yarder PENZSAUR K301-T, System 2 - escavator Caterpillar 320L and yarder Koller).

As diferenças encontradas na atividade de acoplamento pode ser explicada pela maior velocidade de deslocamento de acoplamento do cabo no carrinho. Para a atividade de deslocamento carregado observou-se maior estabilidade na operação com o Sistema 2, fato explicado pelas características de maior potência, peso e área de rodado em contato com o solo no Sistema 2, proporcionando maiores velocidades de trabalho.

Em média, os resultados das atividades foram similares aos encontrados por Paula et al. (2014). Entretanto, Oliveira (2009) obteve maiores percentuais para a atividade de carregamento. 
O aumento da distância de extração aumentou o tempo de ciclo (Figura 3), tal resultado é atribuído a redução da produtividade e é possível notar que o Sistema 2 demandou menor tempo para completar o ciclo de operação, conforme o aumento da distância de extração.

A Figura 4 apresenta a modelagem da produtividade dos sistemas de cabos aéreos. O aumento da distância de extração ocasionou redução na produtividade devido ao maior tempo do ciclo, fato ressaltado por Simões, Fenner e Bantel (2010).

As equações de produtividade dos sistemas confirmam maiores rendimentos em menores distâncias de extração e o Sistema 2 obteve maior produtividade. Considerando a distância média de extração de 150 $\mathrm{m}$, a modelagem expõe produtividades de $13,63 \mathrm{~m}^{3} \mathrm{~h}^{-1}$ para o Sistema 1 e $14,70 \mathrm{~m}^{3} \mathrm{~h}^{-1}$ para o Sistema 2, resultados similares aos encontrados por Simões, Fenner e Bantel (2010), avaliando cabo aéreo similar ao do Sistema 1 deste estudo.

O consumo médio de combustível do trator Massey Fergusson foi de 3,0 $\mathrm{L} \mathrm{h}^{-1}$ e da escavadora Caterpillar foi de $4,0 \mathrm{~L} \mathrm{~h}^{-1}$, estes consumos são considerados baixos, pois as máquinas operam em rotações reduzidas.

Em média, a eficiência operacional foi de $46 \%$ no Sistema 1 e $51 \%$ para o Sistema 2, a disponibilidade mecânica foi de $91 \%$ e 59\%, respectivamente. A menor disponibilidade mecânica do Sistema 2 justifica-se pelo reaproveitamento de uma escavadora utilizada em outras atividades florestais, exigindo manutenções e reparos constantes. A menor eficiência operacional do presente estudo é justificada pelos atrasos no início das operações em virtude da montagem do cabo aéreo e pelas pausas prolongadas no trabalho no Sistema 1. Ao se comparar os resultados deste estudo aos obtidos por Oliveira (2009), observa-se que o autor obteve menor produtividade para distâncias de extração similares e maior eficiência operacional com o cabo aéreo K300. A menor produtividade obtida pelo autor pode ser atribuída à maior declividade do terreno, mesmo apresentando árvores de maiores volumes. Já Lopes et al. (2011), avaliando o cabo aéreo K-601, obtiveram produtividade maior que a do presente estudo, este fato pode ser explicado pelas características de maior potência, capacidade de carga do cabo aéreo e pelas árvores de maiores volumes.

Avaliando o guindaste Terex RT230 na extração de madeira de eucalipto em região montanhosa, Leite et al. (2012) obtiveram na produtividade, valores similares aos encontrados no Sistema 1 e menores valores em comparação ao Sistema 2, para distância de 78 m, porém, o guindaste empilha a madeira, deixando-a pronta para o transporte, não necessitando de outra máquina. Por meio da modelagem dos trabalhos, quando se estende a distância de extração para $150 \mathrm{~m}$, os cabos aéreos, apresentaram produtividade maior de $46 \%$ e $61 \%$ para os Sistemas 1 e 2 deste estudo, além de menor consumo de combustível em relação ao guindaste.

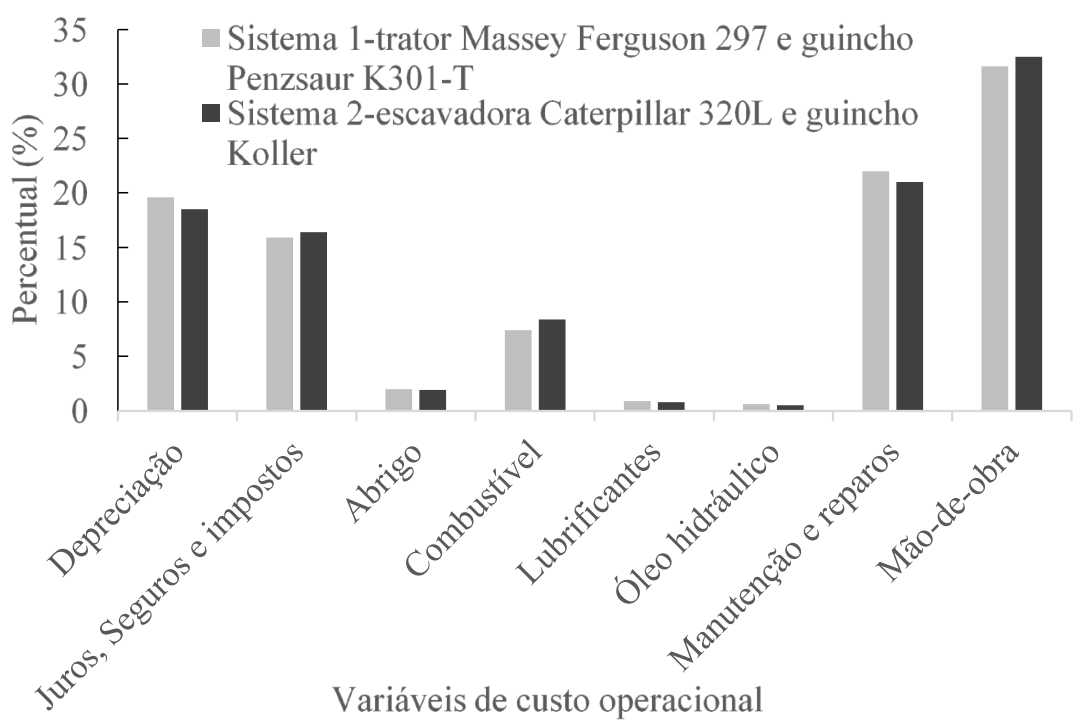

FIGURA 5: Percentual dos custos operacionais dos sistemas de cabos aéreos.

FIGURE 5: Percentage of operational costs of cable yarder systems. 


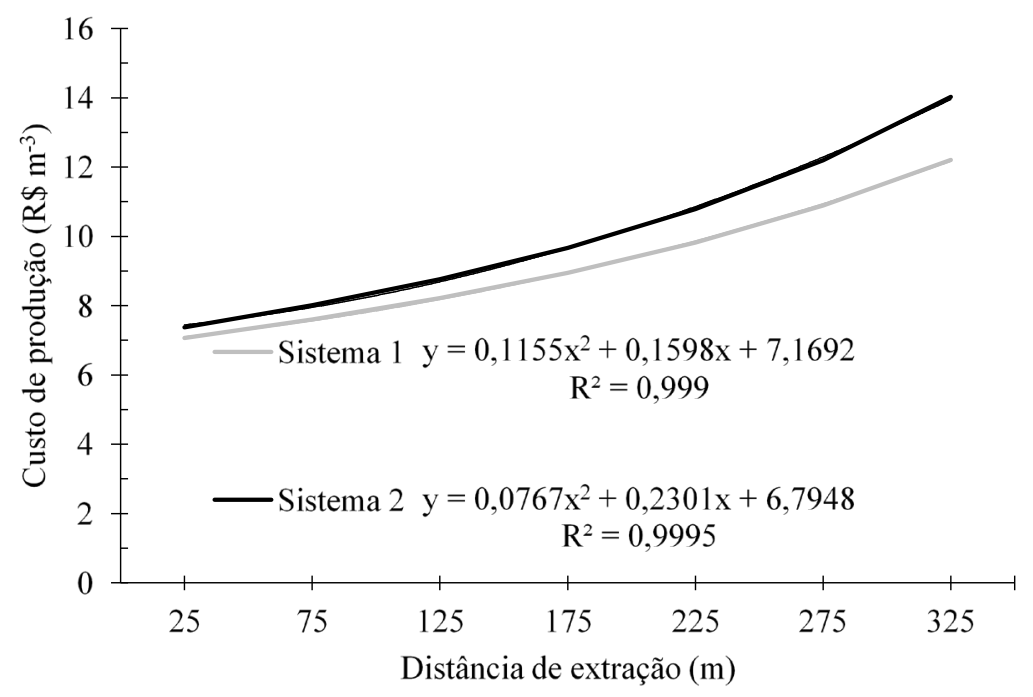

FIGURA 6: Custos de produção em função da distância de extração dos sistemas de cabos aéreos (Sistema 1- trator Massey Ferguson 297 e guincho Penzsaur K301-T, Sistema 2 - escavadora Caterpillar 320L e guincho Koller).

FIGURE 6: Production costs in function on the distance of extraction of cable yarder systems (System 1- tractor Massey Ferguson 297 and yarder PENZSAUR K301-T, System 2 - escavator Caterpillar 320L and yarder Koller).

Desta forma, os sistemas de cabos aéreos destacam-se como alternativa viável na extração de madeira.

Os custos totais foram $\mathrm{R} \$ 116,78 \mathrm{~h}^{-1}$ para o Sistema 1 , destes $37,5 \%$ foram de custos fixos e $62,5 \%$ de custos variáveis e R $\$ 138,16 \mathrm{~h}^{-1}$ para o Sistema 2, sendo $36,8 \%$ de custos fixos e $63,2 \%$ de custos variáveis. Na Figura 5 estão apresentados os valores das variáveis dos custos, sendo os custos de mão de obra e manutenção e reparos de maior representatividade. Os custos foram maiores que os encontrados por Oliveira (2009) e menores que os encontrado por Simões, Fenner e Bantel (2010) e Lopes et al. (2011), entretanto Lopes et al. (2011) obtiveram percentuais de custos fixos e variáveis similares ao deste estudo.

A Figura 6 apresenta a modelagem dos custos de extração em função a distância de extração. $O$ custo médio para o Sistema 1 foi de $\mathrm{R} \$ 9,25 \mathrm{~m}^{-3}\left(\mathrm{US} \$ 2,98 \mathrm{~m}^{-3}\right)$ e $\mathrm{R} \$ 10,12 \mathrm{~m}^{-3}\left(\mathrm{US} \$ 3,26 \mathrm{~m}^{-3}\right.$ ) para o Sistema 2. Observa-se que os custos aumentam com a distância de extração e os custos de produção do Sistema 1 foi $9 \%$ menor que o Sistema 2, apesar de ter apresentado maior produtividade. Este fato é explicado pela necessidade de mais um ajudante para realização da soltura dos cabos e pelo maior valor da máquina no Sistema 2. Estes resultados foram menores que os encontrados por Simões, Fenner e Bantel (2010). Lopes et al. (2011) encontraram valores intermediários aos sistemas de cabos aéreos deste estudo.

\section{CONCLUSÕES}

O carregamento demandou maior tempo no ciclo operacional dos cabos aéreos. O aumento da distância de extração aumentou os tempos do ciclo operacional e as atividades de acoplamento, deslocamento carregamento e descarregamento, foram maiores para o Sistema 1.

$\mathrm{O}$ aumento da distância de extração resultou em redução da produtividade e aumento no custo de produção dos sistemas de cabos aéreos. O Sistema 2 apresentou maior produtividade e maior custo de produção.

\section{REFERÊNCIAS}


AMERICAN SOCIETY OF AGRICULTURAL ENGINEERS. ASAE standards 2001: machinery, equipment and buildings: operating costs. Iowa: Ames, 2001. p. 164-226.

BIRRO, M. H. B. et al. Avaliação técnica e econômica da extração de madeira de Eucalipto com "trackskidder" em região montanhosa. Revista Árvore, Viçosa, MG, v. 26, n. 5, p. 525-532, 2002.

CONWAY, S. Logging practices: principles of timber harvesting systems. São Francisco: Miller Freeman, 1976. $416 \mathrm{p}$.

LEITE, E. S. et al. Utilização de guindaste na extração de madeira em região montanhosa. Revista Árvore, Viçosa, MG, v. 36, n. 1, p. 195-201, 2012.

LOPES, E. S. Aplicação do programa SNAP III (Schedulingand Network AnalysisProgram) no planejamento da colheita e do transporte florestal. 2001. 150 f. Tese (Doutorado em Ciência Florestal) - Universidade Federal de Viçosa, Viçosa, MG, 2001.

LOPES, E. S. et al. Avaliação técnica e de custos de um sistema de cabos aéreos na extração de Pinus taedaL. em região montanhosa. Scientia Forestalis, Piracicaba, v. 39, n. 91, p. 387-394, 2011.

MACHADO, C. C. Exploração florestal. Viçosa: UFV, 1989. v. 6.

OLIVEIRA, R. J. Avaliação técnica e econômica de cabos aéreos na colheita de pinus no município de Cedro Azul - PR. 2009. 54 f. Dissertação (Mestrado em Engenharia Agrícola) - Universidade Federal de Viçosa, Viçosa, MG, 2009.

PAULA, E. N. S. O. et al. Análise operacional da extração florestal com cabos aéreos em floresta de eucalipto. Nativa, Sinop, v. 2, n. 4, p. 234-238, 2014.

PENNA, E. S. Avaliação ergonômica e ambiental de cabos aéreos na colheita de pinus em Cerro Azul, PR. 2009. 155 f. Dissertação (Mestrado em Ciência Florestal) - Universidade Federal de Viçosa, Viçosa, MG, 2009.

SAS INSTITUTE. SAS user's guide: statistics, version 9.2. Cary, 2011.

SIMÕES, D.; FENNER, P. T.; BANTEL, C. A. Custos e rendimentos operacionais da extração de madeira com cabo aéreo. Cerne, Lavras, v. 16, n. 2, p. 185-192, 2010.

SOIL SURVEY STAFF. Keys to soil taxonomy. 11. ed. Washington: Natural Resources Conservation Service, 2010. 